Revue européenne des migrations internationales

vol. $23-n^{\circ} 3$ | 2007

Migrations internationales et vulnérabilités

\title{
Alain TARRIUS, La remontée des Sud. Afghans et Marocains en Europe méridionale
}

Lamia Missaoui

\section{OpenEdition}

Édition électronique

URL : https://journals.openedition.org/remi/4232

DOI : $10.4000 /$ remi.4232

ISSN : $1777-5418$

Éditeur

Université de Poitiers

Édition imprimée

Date de publication : 1 décembre 2007

Pagination : 206-208

ISBN : 978-2-911627-47-4

ISSN : 0765-0752

Référence électronique

Lamia Missaoui, "Alain TARRIUS, La remontée des Sud. Afghans et Marocains en Europe méridionale », Revue européenne des migrations internationales [En ligne], vol. 23 - n³ | 2007, mis en ligne le 27 novembre 2008, consulté le 14 avril 2022. URL : http://journals.openedition.org/remi/4232 ; DOI https://doi.org/10.4000/remi.4232

Ce document a été généré automatiquement le 14 avril 2022.

(c) Université de Poitiers 


\title{
Alain TARRIUS, La remontée des Sud. Afghans et Marocains en Europe méridionale
}

\author{
Lamia Missaoui
}

\section{RÉFÉRENCE}

Alain TARRIUS, La remontée des Sud. Afghans et Marocains en Europe méridionale, Éditions de l'Aube, 2007, 202 p., ISBN 9782752603685

1 À sa façon de livrer des analyses rigoureuses des mobilités transnationales sous la forme plaisante d'écrits de voyage, Alain Tarrius nous propose deux terrains menés de 2002 à 2006 à l'ouest puis à l'est de la Méditerranée. D'abord il reprend et complète ses recherches, déjà exposées dans La mondialisation par le bas ${ }^{1}$ concernant les transmigrants pendulaires Marocains circulant en Andalousie, le long des côtes méditerranéennes du Levant espagnol et du Sud de la France, et au nord de l'Italie ; puis il livre un terrain nouveau, et inattendu dans le contexte actuel des représentations du Sud Est européen, des circulants transnationaux Afghans en perpétuelles rotations par l'Iran, la Turquie ou le Caucase, vers la Bulgarie et la zone des « territoires sans État » de Macédoine, du Kosovo et d'Albanie.

2 Au plaisir de la lecture des difficiles modalités d'entrée dans ces terrains complexes et des descriptions des situations d'interactions, échanges, transactions, accompagnements divers, s'ajoute celui du déploiement d'une méthodologie rigoureuse, inspirée, depuis 1989, par sa double affirmation, d'une part de la primauté de l'étude des mobilités pour l'approche des faits migratoires, d'autre part de la mise en question des présupposés usuels en sciences sociales consistant à survaloriser la sédentarité locale comme source quasi exclusive des hiérarchies identitaires et sociales. Enfin, alors que tant «d'experts en mondialisation» produisent aujourd'hui des registres d'hypothèses sans véritables terrains, il est heureux de constater qu'Alain 
Tarrius ne nous propose de concepts nouveaux, méthodologiques ou théoriques, qu'extrêmement articulés sur les observations qu'il nous livre... C'est ainsi qu'il progresse de recherche en recherche vers une grande aisance dans l'analyse des mouvements mondialisés des populations migrantes. Clefs dont se saisissent heureusement des doctorants de plus en plus nombreux. En effet les deux notions qu'il propose depuis longtemps et améliore à chaque livraison de recherche, le paradigme de la mobilité et, conséquemment, les territoires circulatoires permettent des analyses des grands mouvements de transmigrants qui ne se limitent pas à l'énoncé des contrastes entre populations locales sédentaires, étrangères ou non, et circulants internationaux, mais mettent en exergue les multiples articulations entre les uns et les autres comme les incompatibilités entre régulations des uns et des autres. Dans ce travail, la « déréification" de la notion de territoire circulatoire, sur laquelle il revient depuis plusieurs années est bien établie : topique, au sens freudien du terme, des échanges, des flux, ce territoire est entre autre le lieu de l'acquisition des savoir-circuler nécessaires à l'agrégation productive de centaines de milliers de migrants petits entrepreneurs que des liens forts de parenté ou de voisinage ne suffiraient pas à promouvoir comme nouveaux acteurs des échanges de la mondialisation contemporaine. Les 160000 Afghans qui passent régulièrement par la Bulgarie y réalisent plus d'un milliard et demi d'euros de chiffre d'affaires - vec des prix de vente à moitié prix de ceux pratiqués en France - dans la seule vente de produits électroniques des majors du Sud Est asiatique, transités, en dérogation des accords de l'OMC par Dubaï, Bakou, etc. À destination presque exclusive du marché des pauvres: "Les grands acteurs économiques de la mondialisation ont besoin des pauvres non seulement comme clients, mais encore comme passeurs, hors des règles et lois de la circulation officielle: il faut atteindre les pays pauvres, les derniers de la classe mondiale, mais aussi les populations pauvres dans les pays riches, les dernières de la classe locale». Tarrius nous dit, dans cet ouvrage, que si la finalité de la mobilisation des riches, bien connue, et des pauvres est bien la puissance des firmes multinationales, les modalités de regroupement des premiers et des seconds, types de liens, technicités, rapports aux pouvoirs, sont antagoniques et suggèrent des perspectives conflictuelles que les thuriféraires de la mondialisation oublient un peu rapidement aujourd'hui.

3 Ces nombreux petits acteurs de la mondialisation ne s'en tiennent pas évidemment à la seule mission que leur assignent les «majors ». Dans les Balkans les allées et venues incessantes des cohortes d'Afghans produisent de l'unité parmi ces populations musulmanes que les historiens nous décrivaient comme dissociées, Turcophones, Pomaks, Albanophones: "si l'OTAN n'agit pas correctement et tente de nous imposer une solution indésirable au Kosovo, lui disaient en octobre 2006 des Albanophones musulmans de Nord-Macédoine accompagnés d'Afghans, alors, comme le Hezbollah vient de le faire au Liban, nous créerons une barrière infranchissable, de l'Albanie au Caucase et au Pakistan ». Et cependant, des responsables politiques européens continuent de penser que la frontière naturelle de l'Europe passe par le Bosphore...

4 Ces populations de transmigrants sont articulées à des villes où sont installés des migrants commerçants sédentaires, Alicante en Espagne et Sofia en Bulgarie, qui se transforment sous l'effet de ces collaborations. Tarrius revisite à cette occasion, certaines productions simmeliennes, ou encore des notions « insuffisantes » - espace de mœurs - de l'École de Chicago pour en dire de nouvelles formulations heuristiques. Afghans comme Marocains se dispersent dès lors qu'ils abordent, en les constituant pour partie, des vastes zones européennes criminogènes, comme l'Andalousie ou les 
territoires «sans État » proches du Kosovo. Là, les destins migratoires des individus peuvent se modifier, passant parfois des réseaux à forte régulation interne des commerçants de produits d'usages licites vers des réseaux mafieux, ou, plus simplement, aidés des passeports achetés aux policiers bulgares, tentant leur chance vers la Grande Bretagne pour rejoindre la migration de travail classique.

5 C'est sur le projet d'analyse, déjà en cours de réalisation, du rôle de ces "zones criminogènes » dans les déploiements actuels des réseaux migratoires en Europe que se termine l'ouvrage... nous promettant donc pour dans deux ou trois années la lecture de la suite de ces remarquables enchaînements de recherche.

\section{AUTEURS}

\section{LAMIA MISSAOUI}

Laboratoire PRINTEMPS, Mcf. de sociologie, Université de Versailles-Saint Quentin en Yvelines 